\title{
A Comprehensive Method for Arriving at Initial Feasible Solution for Optimization Problems in Engineering with Illustrative Examples
}

\section{Chandrasekhar Putcha ${ }^{a}$, Ali Shekaramiz}

\author{
aProfessor, Department of Civil and Environmental Engineering, California State University, Fullerton, CA, \\ USA. \\ ${ }^{\mathrm{b}}$ Formerly Graduate Student, Department of Civil and Environmental Engineering, California State University, \\ Fullerton, CA, USA.
}

Article History: Received: 11 January 2021; Accepted: 27 February 2021; Published online: 5 April 2021

\begin{abstract}
Two methods have been used extensively for arriving at initial basic feasible solution (IBF). One of them is Northwest corner rule and the other on is Russell method (Hillier \& Lieberman, 2005.) Both methods have drawbacks. The IBF obtained is either far from optimal solution or does not have adequate number of entries to initiate transportation simplex algorithm. The Northwest Corner rule gives an initial feasible solution that is far from optimal while the IBF solution obtained using Russell method doesn't give enough number of entries to start the transportation simplex algorithm. Hence, there is a need for developing a method for arriving at initial basic feasible solution with adequate number of entries needed to initiate transportation simplex algorithm, which can then be used to get an optimal solution. A computer software has been developed based on the new proposed method for this purpose. The proposed new method has been validated through four simple but illustrative examples.
\end{abstract}

Keywords: Optimization, Basic Feasible Solution, Transportation Problem, Algorithm, Solution, Methods.

\section{Introduction}

There are two most popular methods used in literature for deriving initial basic feasible solution (IBF). One of them is Northwest corner rule for a given transportation problem. Russell method does not give adequate number of entries for IBF $(\mathrm{M}+\mathrm{N})$ entries needed to initiate transportation simplex algorithm. Here $\mathrm{M}$ represents number of rows and $\mathrm{N}$ represents number of columns of the given transportation problem. Some of the entries of IBF have to be made using the demand and supply requirements. In addition some of the zero entries of IBF are entered rather arbitrarily. This gives some IBF which are far from optimal solution. To begin constructing an initial BF solution, all source rows and destination columns of the transportation simplex tableau are initially under consideration for providing a basic variable (allocation). Construction if IBF involves the following steps (Hillier and Lieberman, 2005). A realistic transportation problem which has significance in railroads as well as airlines was studied by (Äüôu 2003). They tested the impact of three factors (moral reasoning, value orientation and risk preference) which varies from person to person, along with three factors (the presence/absence of audits, tax inequity, and peer reporting behavior) that depends upon situation having effect on tax compliance. These factors are statistically significant and it also influences tax compliance behavior. A solution for transportation problem (Halawa et al. 2016) based on computation modeling; unique algorithm was developed for minimizing cost of shipping products from one location to another. It was implemented to find optimal solution in transportation problem as manual computation might encounter several mistakes and consume time and efforts. Results obtained were accurate and validated when compared to that of manually calculated results. An approximated optimized solution to transportation problem which were constrained to transport simulations was solved with iteration (Flötteröd 2017). A probabilistic, asymptotic performance bounds were established, exploited for efficient heuristic formulation and tailored towards an unyielding computational budgets. This method is compatible simulators of broad range requiring minimum parameterization. A new optimization model was recommended to encompass pricing, greenhouse gas emission and planning of operation (Zhang et al. 2019) to maximize rail operator profit along with minimizing customers waiting queue. A case study was carried out to validate the proposed model for improving rail freight service quality and reducing the emission of harmful greenhouse gases. An arithmetical method was illustrated (Gleyzal 1955) which can solve transportation problem by combining ideas, besides to the theory of linear inequalities. A mathematical model was formulated (Zak et al. 2009) for vehicle assignment problem in terms of multi objective optimization which is solved in a step-wise procedure. First step progressed with efficient (Pareto-optimal) samples generated using Pareto Memetic Algorithm (PMA). Second step progressed with reviewing and evaluating the sample by Decision Maker (DM), analysis was done by multiple criterion method through Light Beam Search (LBS) method. The supply of goods from source to destination to minimize shipping cost while fulfilling the supply limit with demand requirements (Hasan 2012). In this technical script author has tried to disclose direct method namely Zero-Suffix Method and 
SAM-Method to determine optimal solution of transportation problem is unable to present optimal solution all the time. The manual and computer methods used for solving transportation problem in mining fields (Ali and Ali 2014). This transportation model presented linear programming problems where the objective was to "transport" goods from different "origins" to various "destinations" so that it is cost-effective. A result showed that Northwest-corner rule can be used in finding optimum solution on the other hand Vogel's approximation method can be used to find more accurate optimum solution. To get feasible and optimal solution of transportation problem an algorithm provides an idea for optimality when compared with MODI method (G.Patel et al. 2017) as the method is stepwise process so that optimum solution is obtained which allow the user to take effective decisions. An optimum solution of transportation problem taken as objective function was determined by the use of Revised Distribution Method on the basis of unit allocation to cells in transportation matrix and Vogel's Approximation Method (Choudhary 2016). A new method to transportation problems was proposed to get optimal solution by arithmetical and logical calculation (Hanif and Rafi 2018) . It is determined that complexity within a shorter period of time is reduced by producing basic solution which can be used while optimizing other constraints. A linear programming was highlighted that can assist managers of Malaysian Trading Company to determine optimized transportation plan which can lead to lowest transportation cost from four polymer supply plants to four different destinations for Malaysian Trading Company. Author also discussed technique for sensitivity analyses of uncertain impact by shipping cost per unit to the total shipping cost fetched by trading company. The cost required for shipping goods was minimized by an integrated algorithm, so that demand was fulfilled by finding optimal solutions to problems in transportation(Abu et al.). The model was tested by an algorithm when different cases of transportation problem were considered. They obtained accurate results and justified it with the results obtained from manual calculations. If North-West corner rule, Minimum Cost Method and Vogel's Approximation Method is compared it can be said three methods gives optimum solution which can be used by researcher according to their requirements for obtaining the number of units transferred from source to destination. A transportation model to minimize the transportation cost using various methods such as TORA, LINGO solver (Yadav and Kumar 2017). A result obtained from the research reveals that proper routing and arrangement of vehicles passing is price saving they have also found materials that are required in proper operation of industry. A method to find optimum solution which requires less iteration when compared with Vogel's approximation method by considering second least value in each row and column (Davda and Patel 2019). The method proposed was efficient for both small and large transportation problem. An optimized solution of transportation problem by the use of fuzzy cost coefficients and for determining the solution an algorithm was proposed (Sets 1996). A transportation problems can be construct suboptimal solutions which are based on solution of averaged problems which are asymptotically optimal (Nikolai 2016). An optimal solution to transportation problem was found by Modi method which is capable to find optimal solution (Sirisha and Viola 2018) when compared with all other transportation problems. A direct analytical method was proposed to find optimal solution to transportation problems. It was established that a numerical illustration to find optimality of results can be yielded by this method as it requires very simple calculations (Ullah et al. 2015). Results obtained by this method show that a solution can be guessed in few iterations and consumes less time. Zero neighboring method can also be used to find feasible solution to transportation problems by an algorithm that proceeds by systematic procedure (Thiagarajan et al. 2013). To find optimum solution to transportation problem MODI method with a few modifications was applied to deteriorated transportation problem to avoid unnecessary iterations (Malireddy 2018). An optimum solution to transportation problem while minimizing the cost by a method which is simple, easy to understand when compared with Vogel's approximation method (Raigar et al. 2017). Issues regarding transportation problem may not be abstained by the aid of assignment to drivers (Seethalakshmy and Srinivasan). Direct Sum Method was proposed to evaluate its efficiency with the results obtained from standard methods. The results confirm that optimum solution of the problem can be easily computed (Gupta 2018). The best and cheapest route in transportation was found where the supply can be used to convince demand of particular points by optimizing three variables (Vivek Joshi 2013). An approach with penalties in row to get feasible solution for transportation problems (Juman and Nawarathne 2019) produced suitable results:

- From the rows and columns still under consideration, select the next basic variable (allocation) according to some criterion.

- Make that allocation large enough to exactly use up the remaining supply in its row or remaining demand in its column (whichever is smaller).

- Eliminate that row or column (whichever had the smaller remaining supply or demand from further consideration. (If the row and column have the same remaining supply and demand, then arbitrarily select the row as the one to be eliminated. The column will be used later to provide a degenerate basic variable, i.e., a circled allocation of zero.)

- If only one row or only one column remains under consideration, then the procedure is completed by selecting every remaining variable (i.e., those variables that were neither previously selected to be basic 
nor eliminated from consideration by eliminating their row or column) associated with that row or column to be basic with the only feasible allocation. Otherwise, return to step 1.

\section{Existing Methodologies}

Basic transportation problem can be stated as

$$
\begin{aligned}
& \text { Minimize } Z=\sum_{i=1}^{m} \sum_{j=1}^{n} c_{i j} x_{i j} \\
& \text { Subject to } \\
& \sum_{j=1}^{n} x_{i j}=s_{i}, \text { for } i=1,2, \ldots, m \\
& \sum_{i=1}^{m} x_{i j}=d_{j}, \text { for } j=1,2, \ldots, n \\
& \text { and } x_{i j} \geq 0, \text { for all } i \text { and } j
\end{aligned}
$$

$\mathrm{s}_{\mathrm{i}}$ and $\mathrm{d}_{\mathrm{j}}$ represent supply and demand variables. The general procedure for IBF is stated below (Hillier \& Lieberman, 2005).

\subsection{Northwest Corner Rule}

Begin by selecting $\mathrm{x}_{11}$ (that is, start in the northwest corner of the transportation simplex tableau). Thereafter, if $\mathrm{x}_{\mathrm{ij}}$ was the last basic variable selected, then next select $\mathrm{x}_{\mathrm{i}, \mathrm{j}+1}$ (that is, move one column to the right) is source $\mathrm{I}$ has any supply remaining. Otherwise, next select $\mathrm{x}_{\mathrm{i}+1, \mathrm{j}}$ (that is, move one row down).

\subsection{Russell Method}

For each source row i remaining under consideration, determine its $u_{\mathrm{i}}$, which is the largest unit cost $\mathrm{c}_{\mathrm{ij}}$ still remaining in that row. For each destination column $\mathrm{j}$ remaining under consideration, determine its $\bar{v}_{\mathrm{j}}$, which is the largest unit cost $c_{\mathrm{ij}}$ still remaining in that column. For each variable $\mathrm{x}_{\mathrm{ij}}$ not previously selected in these rows and columns, calculate $\Delta_{i j}=c_{i j}-\overline{u_{i}}-\overline{v_{j}}$. Select the variable having the largest (in absolute term) negative value of $\Delta_{i j}$. (Ties may be broken arbitrarily.)

\subsection{Proposed New Method}

The basic methodology for the new method is given below:

- For each source row i remaining under consideration, determine its $\bar{u}_{\mathrm{i}}$, which is the largest unit cost $\mathrm{c}_{\mathrm{ij}}$ still remaining in that row .

- For each destination column $\mathrm{j}$ remaining under consideration, determine its $\bar{v}_{\mathrm{j}}$, which is the largest unit cost $c_{i j}$ still remaining in that column.

- For each variable $\mathrm{x}_{\mathrm{ij}}$ not previously selected in these rows and columns, calculate $\Delta_{i j}=c_{i j}-\overline{u_{i}}-\overline{v_{j}} \cdot(4$

- Sort the variables from the largest (in absolute term) negative value of $\Delta_{i j}$ to the smallest (in absolute term) negative value of $\Delta_{i j}$.

- Rank number one to the largest (in absolute term) negative value of $\Delta_{i j}$ and so on.

- Only variables which are being ranked $1 \& 2$ are considered in this method.

- Now from the rows and columns under consideration, select the next basic variables as per ranking decided in step 6 .

- Make that allocation large enough to exactly use up the remaining supply in its row or the remaining demand in its column (whichever is smaller)

- Eliminate that row or column (which ever had the smaller remaining supply or demand) from further consideration. (if row and column have the same remaining supply and demand, then arbitrarily select row as the one to be eliminated. The column will be used later to provide a degenerate basic variable. 
- If only one row or only one column remains under consideration, then the procedure is completed by selecting every remaining variable (i.e. Those variables that were neither previously selected to be basic nor eliminated from consideration by eliminating their row or column) associated with that row or column to be basic with the only feasible allocation.

- Remove excessive zeros (without any loss of generality) once the number of required entries $(m+n-1)$ are obtained.

A computer software has been developed based on the steps outlined above. Four examples have been solved based on the new method as follows:

\subsection{Theoretical Basis of the Proposed New Method}

The theoretical basis is exactly same as that for Russel method. The important thing to be noted is that by picking 2 entries for every iteration, the IBF obtained gives the required number of entries to start the chain reaction to get optimal solution.

Example 1. Consider the transportation problem in Civil engineering having the supply-demand requirements.

\begin{tabular}{|c|c|c|c|c|c|c|}
\hline$x$ & 1 & & & & & SUPPLY \\
\hline 1 & 16 & 16 & 13 & & 17 & 50 \\
\hline 2 & 14 & 14 & 13 & & 15 & 60 \\
\hline 3 & 19 & 19 & 20 & & M & 50 \\
\hline 4 & M & 0 & M & & 0 & 50 \\
\hline DEMAND & 30 & & & & & z \\
\hline
\end{tabular}

Construct the $\bar{U}_{\mathrm{s}}$ and $\bar{V}_{\mathrm{s}}$ based on step 2

Table 1.2. The Largest Unit Cost $\mathrm{c}_{\mathrm{ij}}$ Remaining in Rows \& Columns

\begin{tabular}{lccccccccc}
\hline ITERATION & $\bar{U}_{1}$ & $\bar{U}_{2}$ & $\bar{U}_{3}$ & $\bar{U}_{4}$ & $\bar{V}_{1}$ & $\bar{V}_{2}$ & $\bar{V}_{3}$ & $\bar{V}_{4}$ & $\bar{V}_{5}$ \\
1 & 22 & 19 & $\mathrm{M}$ & $\mathrm{M}$ & $\mathrm{M}$ & 19 & $\mathrm{M}$ & 23 & $\mathrm{M}$ \\
\hline
\end{tabular}

Calculate $\Delta_{i j}=c_{i j}-\overline{u_{i}}-\overline{v_{j}}$ and rank them based on step $6 \& 7$

Table 1.3. $\Delta_{i j}$ \& Ranks

\begin{tabular}{cc}
\hline$\Delta_{i j}$ & $R A N K$ \\
\hline$\Delta_{45}$ & 1 \\
$\Delta_{31}$ & 2 \\
$\Delta_{33}$ & 3 \\
$\Delta_{44}$ & 4 \\
$\Delta_{42}$ & 5 \\
$\Delta_{13}$ & 6 \\
$\Delta_{11}$ & 7 \\
$\Delta_{23}$ & 7 \\
$\Delta_{15}$ & 9 \\
$\Delta_{21}$ & 9 \\
$\Delta_{25}$ & 11 \\
$\Delta_{32}$ & 12 \\
$\Delta_{34}$ & 12 \\
$\Delta_{35}$ & 12 \\
$\Delta_{41}$ & 12 \\
$\Delta_{43}$ & 12 \\
$\Delta_{12}$ & 17 \\
$\Delta_{22}$ & 18 \\
$\Delta_{14}$ & 19
\end{tabular}


First cell allocation $\mathrm{C}_{45}$ based on step 8 use a value of 50 . $2^{\text {nd }}$ Cell allocation $\mathrm{C}_{31}$ based on step 8 use value of 30 .

\begin{tabular}{|c|c|c|c|c|c|c|c|c|}
\hline$x$ & \multicolumn{2}{|r|}{1} & 2 & 3 & 4 & \multicolumn{2}{|r|}{5} & SUPPLY \\
\hline 1 & 16 & & 16 & 13 & 22 & 17 & & 50 \\
\hline 2 & 14 & & 14 & 13 & 19 & 15 & & 60 \\
\hline 3 & 19 & 30 & 19 & 20 & 23 & M & & 50 \\
\hline 4 & M & & 0 & M & 0 & 0 & 50 & 50 \\
\hline DEMAND & & 30 & & & & & 60 & Z \\
\hline
\end{tabular}

Table 1.5. The Largest Unit Cost $c_{i j}$ Remaining in Rows \& Columns

\begin{tabular}{llllllllll}
\hline ITERATION & $\bar{U}_{\mathbf{1}}$ & $\bar{U}_{\mathbf{2}}$ & $\bar{U}_{\mathbf{3}}$ & $\bar{U}_{\mathbf{4}}$ & $\bar{V}_{\mathbf{1}}$ & $\bar{V}_{\mathbf{2}}$ & $\bar{V}_{\mathbf{3}}$ & $\bar{V}_{\mathbf{4}}$ & $\bar{V}_{\mathbf{5}}$ \\
2 & 22 & 19 & $\mathrm{M}$ & - & - & 19 & 20 & 23 & $\mathbf{M}$ \\
\hline
\end{tabular}

Table 1.6. $\Delta_{i j} \&$ Ranks

\begin{tabular}{cc}
\hline$\Delta_{i j}$ & $\boldsymbol{R A N K}$ \\
\hline$\Delta_{15}$ & 1 \\
$\Delta_{25}$ & 2 \\
$\Delta_{32}$ & 3 \\
$\Delta_{34}$ & 3 \\
$\Delta_{35}$ & 3 \\
$\Delta_{45}$ & 3 \\
$\Delta_{33}$ & 7 \\
$\Delta_{31}$ & 8 \\
$\Delta_{13}$ & 10 \\
$\Delta_{23}$ & 10 \\
$\Delta_{12}$ & 11 \\
$\Delta_{22}$ & 12 \\
$\Delta_{14}$ & 13 \\
$\Delta_{24}$ & 13 \\
$\Delta_{44}$ & 13 \\
$\Delta_{42}$ & 16 \\
$\Delta_{11}$ & 17 \\
$\Delta_{21}$ & 18 \\
$\Delta_{43}$ & 19 \\
$\Delta_{41}$ & 20 \\
\hline &
\end{tabular}


A Comprehensive Method for Arriving at Initial Feasible Solution for Optimization Problems in Engineering with Illustrative Examples

First cell allocation $\mathrm{C}_{15}$ based on step 8 use value of 10 .

$2^{\text {nd }}$ Cell allocation $\mathrm{C}_{25}$ based on step 8 use value of 0 .

\begin{tabular}{|c|c|c|c|c|c|c|c|c|c|c|c|}
\hline \multirow{2}{*}{$\frac{x}{1}$} & \multicolumn{2}{|r|}{1} & \multicolumn{2}{|c|}{2} & \multicolumn{2}{|r|}{3} & \multicolumn{2}{|r|}{4} & \multicolumn{2}{|r|}{5} & \multirow{2}{*}{$\begin{array}{c}\text { SUPPLY } \\
50\end{array}$} \\
\hline & 16 & & 16 & & 13 & & 22 & & 17 & 10 & \\
\hline 2 & 14 & & 14 & & 13 & & 19 & & 15 & 0 & 60 \\
\hline 3 & 19 & 30 & 19 & & 20 & & 23 & & M & & 50 \\
\hline 4 & M & & 0 & & M & & 0 & & 0 & 50 & 50 \\
\hline DEMAND & & 30 & & 20 & & 70 & & 30 & & 60 & Z \\
\hline
\end{tabular}

Table 1.8. The Largest Unit Cost $c_{i j}$ Remaining in Rows \& Columns

\begin{tabular}{llllllllll} 
ITERATION & $\bar{U}_{\mathbf{1}}$ & $\bar{U}_{\mathbf{2}}$ & $\bar{U}_{\mathbf{3}}$ & $\bar{U}_{\mathbf{4}}$ & $\bar{V}_{\mathbf{1}}$ & $\bar{V}_{\mathbf{2}}$ & $\bar{V}_{\mathbf{3}}$ & $\bar{V}_{\mathbf{4}}$ & $\bar{V}_{\mathbf{5}}$ \\
3 & 22 & 19 & 23 & - & - & 19 & 20 & 23 & - \\
\hline
\end{tabular}

Table 1.9. $\Delta_{i j} \&$ Ranks

\begin{tabular}{ll}
\hline$\Delta_{i j}$ & $\boldsymbol{R A N K}$ \\
\hline$\Delta_{13}$ & 1 \\
$\Delta_{12}$ & 2 \\
$\Delta_{22}$ & 3 \\
$\Delta_{14}$ & 4 \\
$\Delta_{24}$ & 4 \\
$\Delta_{32}$ & 4 \\
$\Delta_{34}$ & 4 \\
$\Delta_{44}$ & 4 \\
$\Delta_{33}$ & 9 \\
$\Delta_{42}$ & 10 \\
$\Delta_{23}$ & 11 \\
$\Delta_{11}$ & 12 \\
$\Delta_{15}$ & 13 \\
$\Delta_{21}$ & 13 \\
$\Delta_{25}$ & 15 \\
$\Delta_{31}$ & 15 \\
$\Delta_{45}$ & 17 \\
$\Delta_{35}$ & 18 \\
$\Delta_{43}$ & 19 \\
$\Delta_{41}$ & 20 \\
\hline &
\end{tabular}


First cell allocation $\mathrm{C}_{13}$ based on step 8 use value of 40 .

$2^{\text {nd }}$ Cell allocations $C_{12}$ based on step 8 use value of 0 .

Table \#1.10- Allocations (Iteration \#3)

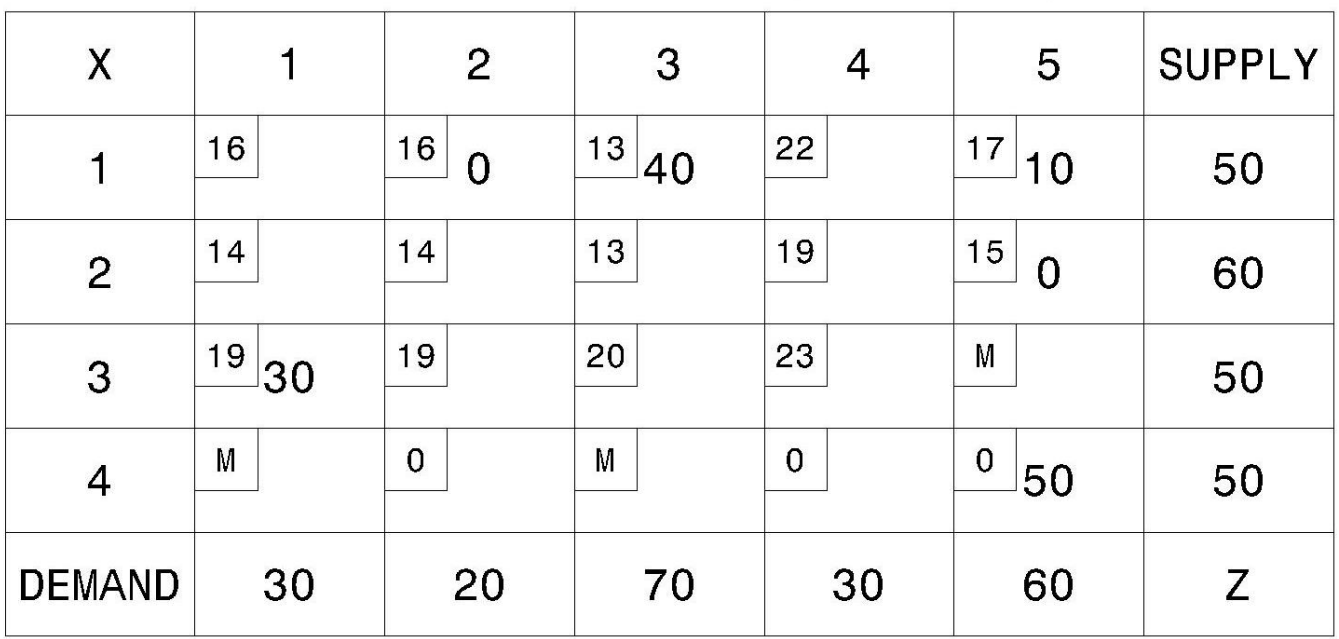

Table 1.11. The Largest Unit Cost $c_{\mathrm{ij}}$ Remaining in Rows \& Columns $\begin{array}{llllllllll}\text { ITERATION } & \bar{U}_{1} & \bar{U}_{2} & \bar{U}_{3} & \bar{U}_{4} & \bar{V}_{1} & \bar{V}_{2} & \bar{V}_{3} & \bar{V}_{4} & \bar{V}_{5}\end{array}$ 4 1923

$1920 \quad 23$

Table 1.12. $\Delta_{i j} \&$ Ranks

\begin{tabular}{ll}
\hline$\Delta_{i j}$ & $\boldsymbol{R A N K}$ \\
\hline$\Delta_{23}$ & 1 \\
$\Delta_{22}$ & 2 \\
$\Delta_{24}$ & 3 \\
$\Delta_{32}$ & 3 \\
$\Delta_{34}$ & 3 \\
$\Delta_{44}$ & 3 \\
$\Delta_{33}$ & 7 \\
$\Delta_{42}$ & 8 \\
$\Delta_{13}$ & 9 \\
$\Delta_{21}$ & 10 \\
$\Delta_{25}$ & 11 \\
$\Delta_{31}$ & 11 \\
$\Delta_{12}$ & 13 \\
$\Delta_{14}$ & 14 \\
$\Delta_{45}$ & 15 \\
$\Delta_{11}$ & 16 \\
$\Delta_{15}$ & 17 \\
$\Delta_{35}$ & 18 \\
$\Delta_{43}$ & 19 \\
$\Delta_{41}$ & 20 \\
\hline
\end{tabular}

First cell allocation is $\mathrm{C}_{23}$, based on step 8 use values of 30 . 
A Comprehensive Method for Arriving at Initial Feasible Solution for Optimization Problems in Engineering with Illustrative Examples

$2^{\text {nd }}$ cell allocation is $C_{22}$ based on step 8 use value of 20 .

Table \#1.13- Allocations (Iteration \#4)

\begin{tabular}{|c|c|c|c|c|c|c|c|c|c|c|}
\hline$x$ & \multicolumn{2}{|r|}{1} & \multicolumn{2}{|r|}{2} & & 3 & 4 & \multicolumn{2}{|r|}{5} & SUPPLY \\
\hline 1 & 16 & & 16 & 0 & 13. & 40 & 22 & 17 & 10 & 50 \\
\hline 2 & 14 & & 14 & 20 & 13 & 30 & 19 & 15 & 0 & 60 \\
\hline 3 & 193 & 30 & 19 & & 20 & & 23 & M & & 50 \\
\hline 4 & M & & 0 & & M & & 0 & 0 & 50 & 50 \\
\hline DEMAND & & 30 & & 20 & & 70 & & & 60 & Z \\
\hline
\end{tabular}

Table 1.14. The Largest Unit Cost $\mathrm{c}_{\mathrm{ij}}$ Remaining in Rows \& Columns

\begin{tabular}{lccccccccc}
\hline ITERATION & $\bar{U}_{1}$ & $\bar{U}_{2}$ & $\bar{U}_{\mathbf{3}}$ & $\bar{U}_{4}$ & $\bar{V}_{\mathbf{1}}$ & $\bar{V}_{2}$ & $\bar{V}_{\mathbf{3}}$ & $\bar{V}_{4}$ & $\bar{V}_{\mathbf{5}}$ \\
5 & - & 19 & 23 & - & - & - & - & 23 & - \\
\hline
\end{tabular}

Table 1.15. $\Delta_{i j} \&$ Ranks

\begin{tabular}{ll}
\hline$\Delta_{i j}$ & $\boldsymbol{R A N K}$ \\
\hline$\Delta_{24}$ & 1 \\
$\Delta_{34}$ & 1 \\
$\Delta_{44}$ & 1 \\
$\Delta_{23}$ & 4 \\
$\Delta_{21}$ & 5 \\
$\Delta_{22}$ & 5 \\
$\Delta_{25}$ & 7 \\
$\Delta_{31}$ & 7 \\
$\Delta_{32}$ & 7 \\
$\Delta_{14}$ & 10 \\
$\Delta_{33}$ & 11 \\
$\Delta_{42}$ & 11 \\
$\Delta_{45}$ & 11 \\
$\Delta_{13}$ & 14 \\
$\Delta_{11}$ & 15 \\
$\Delta_{12}$ & 15 \\
$\Delta_{15}$ & 17 \\
$\Delta_{35}$ & 18 \\
$\Delta_{41}$ & 19 \\
$\Delta_{43}$ & 19 \\
\hline &
\end{tabular}

First cell allocations are $\mathrm{C}_{24}$ and $\mathrm{C}_{34}$ as only two entries are to be used at each iteration based on step 8 use values of 10 and 20. 
No need of entry corresponding to $\mathrm{C}_{44}$ as there are $(m+n-1)$ entries already in the allocation table. Table \#1.16- Allocations (Iteration \#5)

\begin{tabular}{|c|c|c|c|c|c|c|c|c|c|c|c|}
\hline$x$ & \multicolumn{2}{|r|}{1} & \multicolumn{2}{|r|}{2} & & 3 & \multicolumn{2}{|r|}{4} & \multicolumn{2}{|r|}{5} & SUPPLY \\
\hline 1 & 16 & & 16 & & 13 & 40 & 22 & & 17 & 10 & 50 \\
\hline 2 & 14 & & 14 & 20 & 13 & 30 & 19 & 10 & 15 & & 60 \\
\hline 3 & 193 & 30 & 19 & & 20 & & 23 & 20 & M & & 50 \\
\hline 4 & M & & 0 & & M & & 0 & & 0 & 50 & 50 \\
\hline DEMAND & & 30 & & 20 & & 70 & & 30 & & 60 & Z \\
\hline
\end{tabular}

Now all the variables are found; therefore, $\mathrm{Z}$ value can be calculated.

$\mathrm{Z}$ value:

$13(40)+17(10)+14(20)+13(30)+19(10)+19(30)+23(20)+0(50)=2630$

\section{Example 2.}

Consider a transportation problem in Civil Engineering having the following supply-demand requirements table

Table \#2.1- Given Values (Cost)

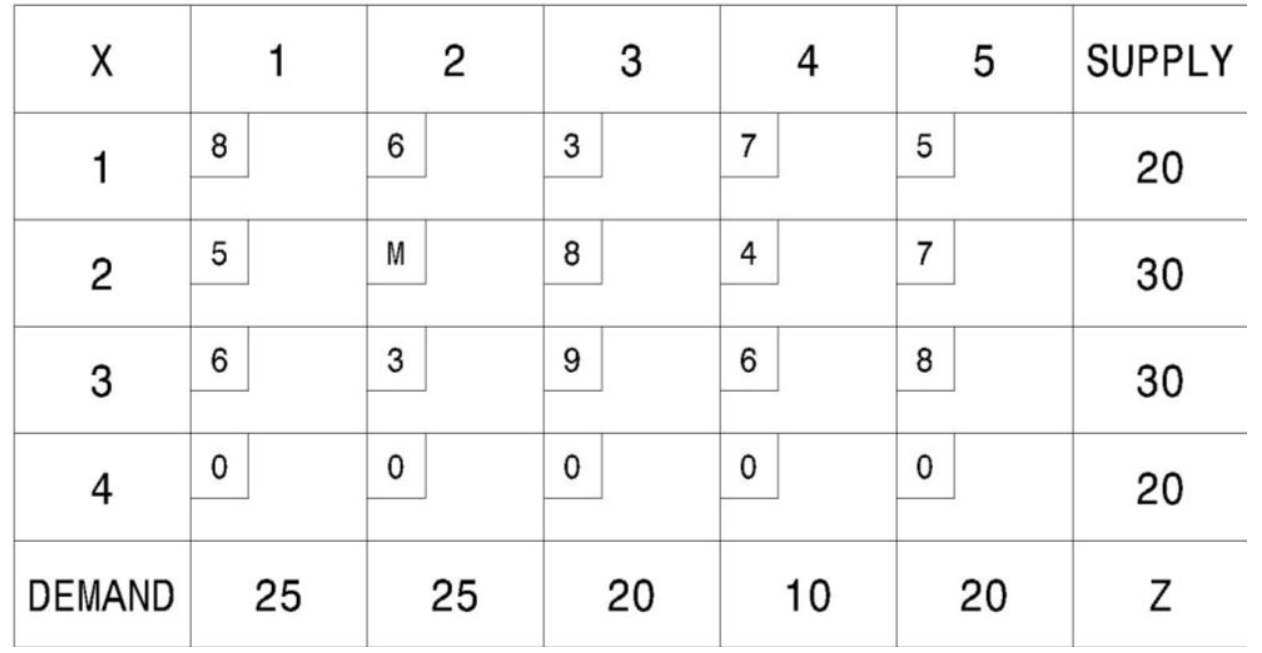

Construct the $\mathrm{U}_{\mathrm{s}}$ and $\mathrm{V}_{\mathrm{s}}$ based on step 2

Table 2.2. The Largest Unit Cost $\mathrm{c}_{\mathrm{ij}}$ Remaining in Rows \& Columns

\begin{tabular}{lllllllllll} 
ITERATION & $\bar{U}_{\mathbf{1}}$ & $\bar{U}_{2}$ & $\bar{U}_{\mathbf{3}}$ & $\bar{U}_{\mathbf{4}}$ & $\bar{V}_{\mathbf{1}}$ & $\bar{V}_{\mathbf{2}}$ & $\bar{V}_{\mathbf{3}}$ & $\bar{V}_{4}$ & $\bar{V}_{\mathbf{5}}$ \\
\hline 1 & 8 & $\mathrm{M}$ & 9 & 0 & 8 & $\mathrm{M}$ & 9 & 7 & 8 \\
\hline
\end{tabular}


A Comprehensive Method for Arriving at Initial Feasible Solution for Optimization Problems in Engineering with Illustrative Examples

Table 2.3. $\Delta_{i j} \&$ Ranks

\begin{tabular}{ll}
\hline$\Delta_{i j}$ & $\boldsymbol{R A N K}$ \\
\hline$\Delta_{32}$ & 1 \\
$\Delta_{21}$ & 2 \\
$\Delta_{24}$ & 2 \\
$\Delta_{12}$ & 4 \\
$\Delta_{23}$ & 5 \\
$\Delta_{25}$ & 5 \\
$\Delta_{22}$ & 7 \\
$\Delta_{42}$ & 7 \\
$\Delta_{13}$ & 9 \\
$\Delta_{33}$ & 10 \\
$\Delta_{15}$ & 11 \\
$\Delta_{31}$ & 11 \\
$\Delta_{34}$ & 13 \\
$\Delta_{35}$ & 14 \\
$\Delta_{43}$ & 14 \\
$\Delta_{11}$ & 16 \\
$\Delta_{14}$ & 16 \\
$\Delta_{41}$ & 16 \\
$\Delta_{45}$ & 16 \\
$\Delta_{44}$ & 20 \\
\hline &
\end{tabular}

First cell allocation $\mathrm{C}_{32}$ based on step 8 use value of 25 .

$2^{\text {nd }}$ Cell allocations $\mathrm{C}_{21}, \mathrm{C}_{24}$ based on step 8 use values of 25 and 5.

Table \#2.4- Allocations (Iteration \#1)

\begin{tabular}{|c|c|c|c|c|c|c|c|c|c|c|}
\hline$x$ & \multicolumn{2}{|r|}{1} & \multicolumn{2}{|r|}{2} & \multicolumn{2}{|c|}{3} & \multicolumn{2}{|r|}{4} & 5 & \multirow{2}{*}{$\begin{array}{c}\text { SUPPLY } \\
20\end{array}$} \\
\hline 1 & 8 & & 6 & & 3 & & 7 & & 5 & \\
\hline 2 & 5 & 25 & M & & 8 & & 4 & 5 & 7 & 30 \\
\hline 3 & 6 & & 3 & 25 & 9 & & 6 & & 8 & 30 \\
\hline 4 & 0 & & 0 & & 0 & & 0 & & 0 & 20 \\
\hline DEMAND & & 25 & & 25 & & 20 & & 10 & & Z \\
\hline
\end{tabular}

Table 2.5. The Largest Unit Cost $\mathrm{c}_{\mathrm{ij}}$ Remaining in Rows \& Columns

\begin{tabular}{lllllllllll}
\hline ITERATION & $\bar{U}_{\mathbf{1}}$ & $\bar{U}_{\mathbf{2}}$ & $\bar{U}_{\mathbf{3}}$ & $\bar{U}_{\mathbf{4}}$ & $\bar{V}_{\mathbf{1}}$ & $\bar{V}_{\mathbf{2}}$ & $\bar{V}_{\mathbf{3}}$ & $\bar{V}_{\mathbf{4}}$ & $\bar{V}_{\mathbf{5}}$ \\
\hline 2 & 7 & - & 9 & 0 & - & - & 9 & 7 & 8 \\
\hline
\end{tabular}


Table 2.6. $\Delta_{i j} \&$ Ranks

\begin{tabular}{ll}
\hline$\Delta_{i j}$ & $\boldsymbol{R A N K}$ \\
\hline$\Delta_{13}$ & 1 \\
$\Delta_{33}$ & 2 \\
$\Delta_{15}$ & 3 \\
$\Delta_{34}$ & 3 \\
$\Delta_{35}$ & 5 \\
$\Delta_{43}$ & 5 \\
$\Delta_{45}$ & 7 \\
$\Delta_{14}$ & 8 \\
$\Delta_{44}$ & 8 \\
$\Delta_{32}$ & 10 \\
$\Delta_{24}$ & 11 \\
$\Delta_{31}$ & 11 \\
$\Delta_{12}$ & 13 \\
$\Delta_{23}$ & 13 \\
$\Delta_{25}$ & 13 \\
$\Delta_{41}$ & 16 \\
$\Delta_{42}$ & 16 \\
$\Delta_{11}$ & 18 \\
$\Delta_{21}$ & 19 \\
$\Delta_{22}$ & 20 \\
\hline
\end{tabular}

First cell allocation is $\mathrm{C}_{13}$, use value of 20 for this cell.

$2^{\text {nd }}$ cell allocation is $\mathrm{C}_{33}$, based on step 8 use values of 0 .

Table \#2.7- Allocations (Iteration \#2)

\begin{tabular}{|c|c|c|c|c|c|c|c|c|c|c|}
\hline$X$ & \multicolumn{2}{|r|}{1} & \multicolumn{2}{|r|}{2} & \multicolumn{2}{|r|}{3} & \multicolumn{2}{|r|}{4} & 5 & SUPPLY \\
\hline 1 & 8 & & 6 & & 3 & 20 & 7 & & 5 & 20 \\
\hline 2 & 5 & 25 & M & & 8 & & 4 & 5 & 7 & 30 \\
\hline 3 & 6 & & 3 & 25 & 9 & 0 & 6 & & 8 & 30 \\
\hline 4 & 0 & & 0 & & 0 & & 0 & & 0 & 20 \\
\hline DEMAND & & 25 & & 25 & & 20 & & 10 & & Z \\
\hline
\end{tabular}

Table 2.8. The Largest Unit Cost $\mathrm{c}_{\mathrm{ij}}$ Remaining in Rows \& Columns 
A Comprehensive Method for Arriving at Initial Feasible Solution for Optimization Problems in Engineering with Illustrative Examples

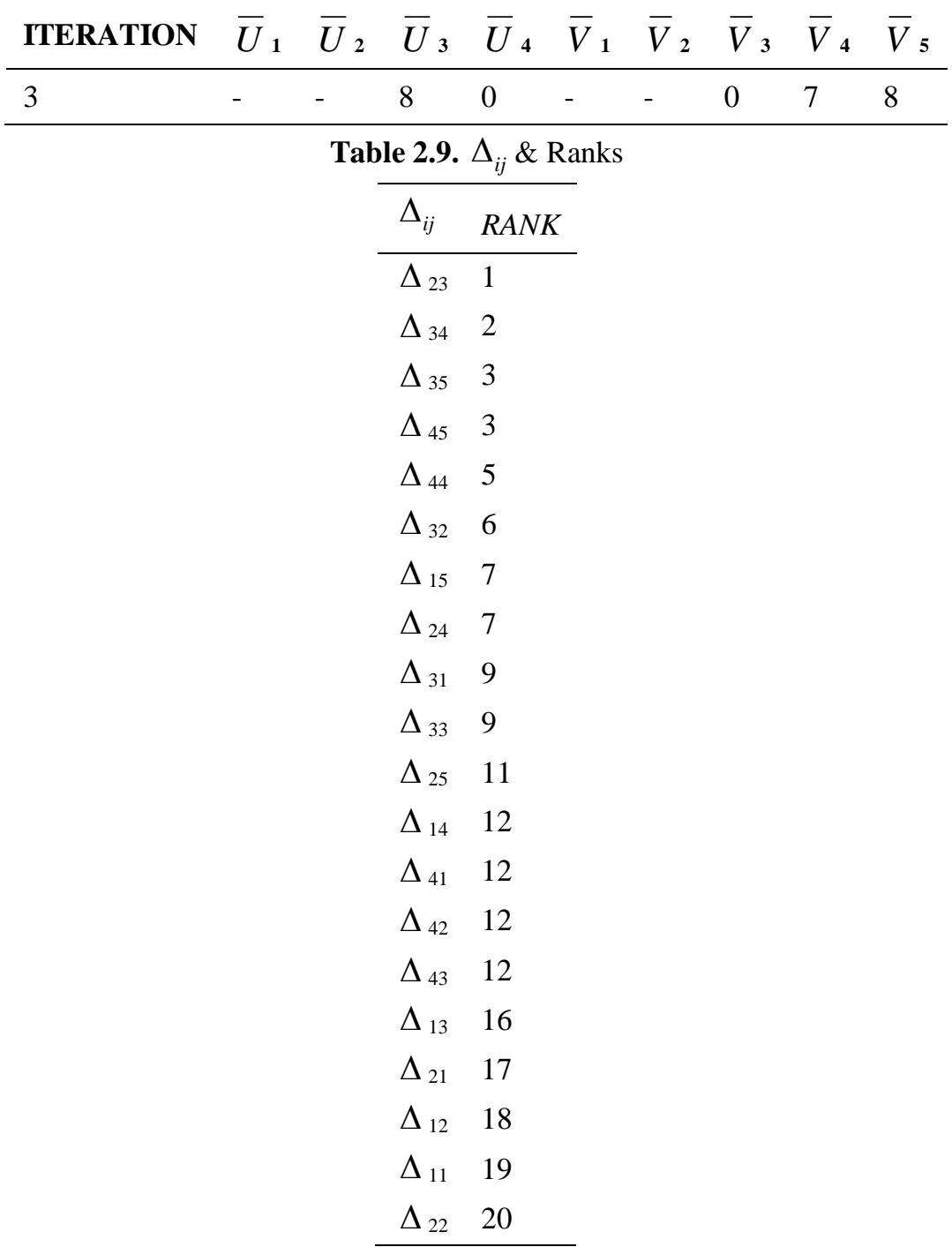

First cell allocation is $\mathrm{C}_{23}$ based on step 8 use values of 0 . $2^{\text {nd }}$ Cell allocation is $\mathrm{C}_{34}$ based on step 8 use values of 5 .

Table \#2.10- Allocations (Iteration \#3)

\begin{tabular}{|c|c|c|c|c|c|c|c|c|c|c|}
\hline$X$ & \multicolumn{2}{|r|}{1} & \multicolumn{2}{|r|}{2} & \multicolumn{2}{|r|}{3} & \multicolumn{2}{|r|}{4} & 5 & SUPPLY \\
\hline 1 & 8 & & 6 & & 3 & 20 & 7 & & 5 & 20 \\
\hline 2 & 5 & 25 & M & & 8 & 0 & 4 & 5 & 7 & 30 \\
\hline 3 & 6 & & 3 & 25 & 9 & 0 & 6 & 5 & 8 & 30 \\
\hline 4 & 0 & & 0 & & 0 & & 0 & & 0 & 20 \\
\hline DEMAND & & 25 & & 25 & & 20 & & 10 & & Z \\
\hline
\end{tabular}

Table 2.11. The Largest Unit Cost $c_{\mathrm{ij}}$ Remaining in Rows \& Columns 


\begin{tabular}{lllllllllll}
\hline ITERATION & $\bar{U}_{1}$ & $\bar{U}_{2}$ & $\bar{U}_{3}$ & $\bar{U}_{4}$ & $\bar{V}_{1}$ & $\bar{V}_{2}$ & $\bar{V}_{3}$ & $\bar{V}_{4}$ & $\bar{V}_{5}$ \\
\hline 4 & - & - & - & 0 & - & - & - & - & 0 \\
\hline
\end{tabular}

Table 2.12. $\Delta_{i j} \&$ Ranks

\begin{tabular}{ll}
\hline$\Delta_{i j}$ & $\boldsymbol{R} \boldsymbol{A N K}$ \\
\hline$\Delta_{41}$ & 1 \\
$\Delta_{42}$ & 1 \\
$\Delta_{43}$ & 1 \\
$\Delta_{44}$ & 1 \\
$\Delta_{45}$ & 1 \\
$\Delta_{13}$ & 6 \\
$\Delta_{32}$ & 6 \\
$\Delta_{24}$ & 8 \\
$\Delta_{15}$ & 9 \\
$\Delta_{21}$ & 9 \\
$\Delta_{12}$ & 11 \\
$\Delta_{31}$ & 11 \\
$\Delta_{33}$ & 11 \\
$\Delta_{34}$ & 11 \\
$\Delta_{14}$ & 15 \\
$\Delta_{25}$ & 15 \\
$\Delta_{11}$ & 17 \\
$\Delta_{23}$ & 17 \\
$\Delta_{35}$ & 17 \\
$\Delta_{22}$ & 20 \\
\hline
\end{tabular}

First cell allocations are $\mathrm{C}_{41}, \mathrm{C}_{42}, \mathrm{C}_{43}, \mathrm{C}_{44}, \mathrm{C}_{45}$ based on step 8 use values of $0,0,0,0$ and 20.

Table \#2.13- Allocations (Iteration \#4)

\begin{tabular}{|c|c|c|c|c|c|c|c|c|c|c|c|}
\hline$X$ & \multicolumn{2}{|r|}{1} & \multicolumn{2}{|r|}{2} & \multicolumn{2}{|r|}{3} & \multicolumn{2}{|r|}{4} & \multicolumn{2}{|r|}{5} & SUPPLY \\
\hline 1 & 8 & & 6 & & 3 & 20 & 7 & & 5 & & 20 \\
\hline 2 & 5 & 25 & M & & 8 & 0 & 4 & 5 & 7 & & 30 \\
\hline 3 & 6 & & 3 & 25 & 9 & 0 & 6 & 5 & 8 & & 30 \\
\hline 4 & 0 & & 0 & & 0 & & 0 & & 0 & 20 & 20 \\
\hline DEMAND & & 25 & & 25 & & 20 & & 10 & & 20 & Z \\
\hline
\end{tabular}

Now all the variables are found and the table is satisfied; therefore, $\mathrm{Z}$ value can be calculated. 
A Comprehensive Method for Arriving at Initial Feasible Solution for Optimization Problems in Engineering with Illustrative Examples

$\mathrm{Z}$ value $=3(20)+5(25)+8(0)+4(5)+3(25)+9(0)+6(5)+20(0)=310$

\section{Example 3.}

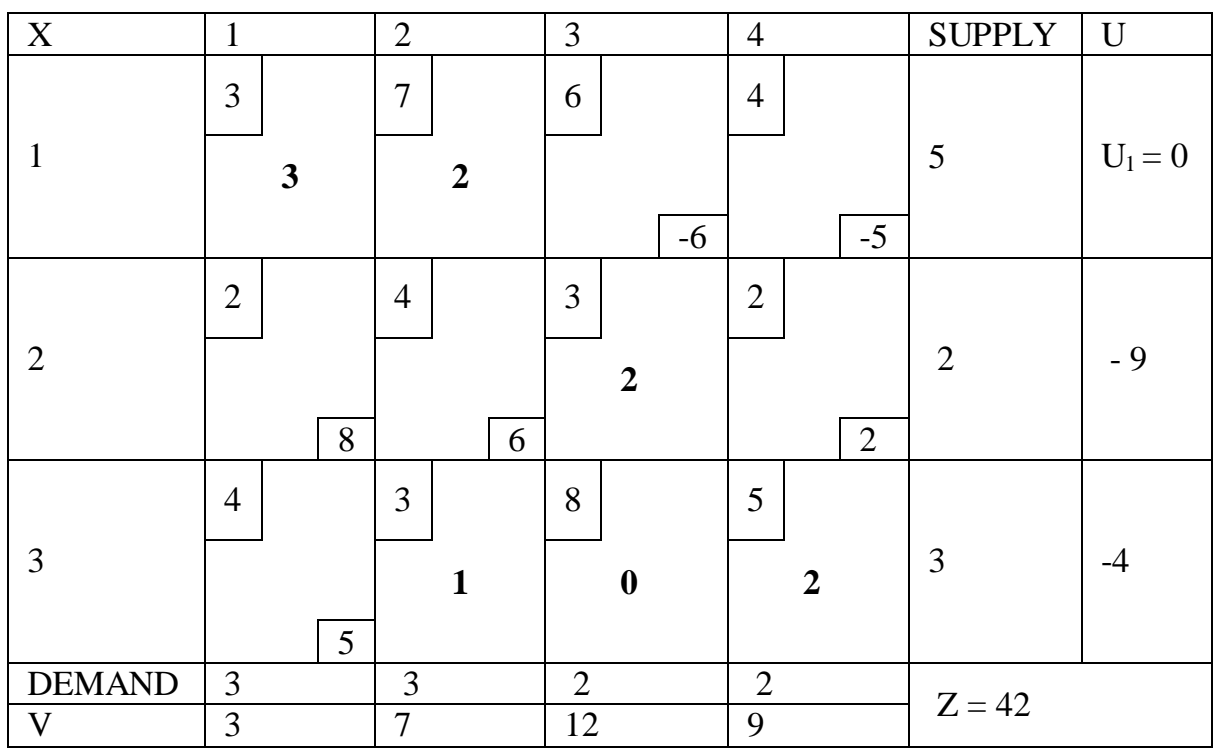

Let, $\mathrm{U}_{1}=0$

$\mathrm{c}_{11}=\mathrm{u}_{1}+\mathrm{v}_{1}$

$\Rightarrow \mathrm{v}_{1}=3$

$\mathrm{c}_{12}=\mathrm{u}_{1}+\mathrm{v}_{2}$

$\Rightarrow \quad v_{2}=7$ and so on.

Here, for all the non basic cells 13 and14 the values of $c_{i j}-u_{i}-v_{j}<0$. So the solution is not optimal.

\section{Example 4.}

Consider the transportation problem having the following parameter table:

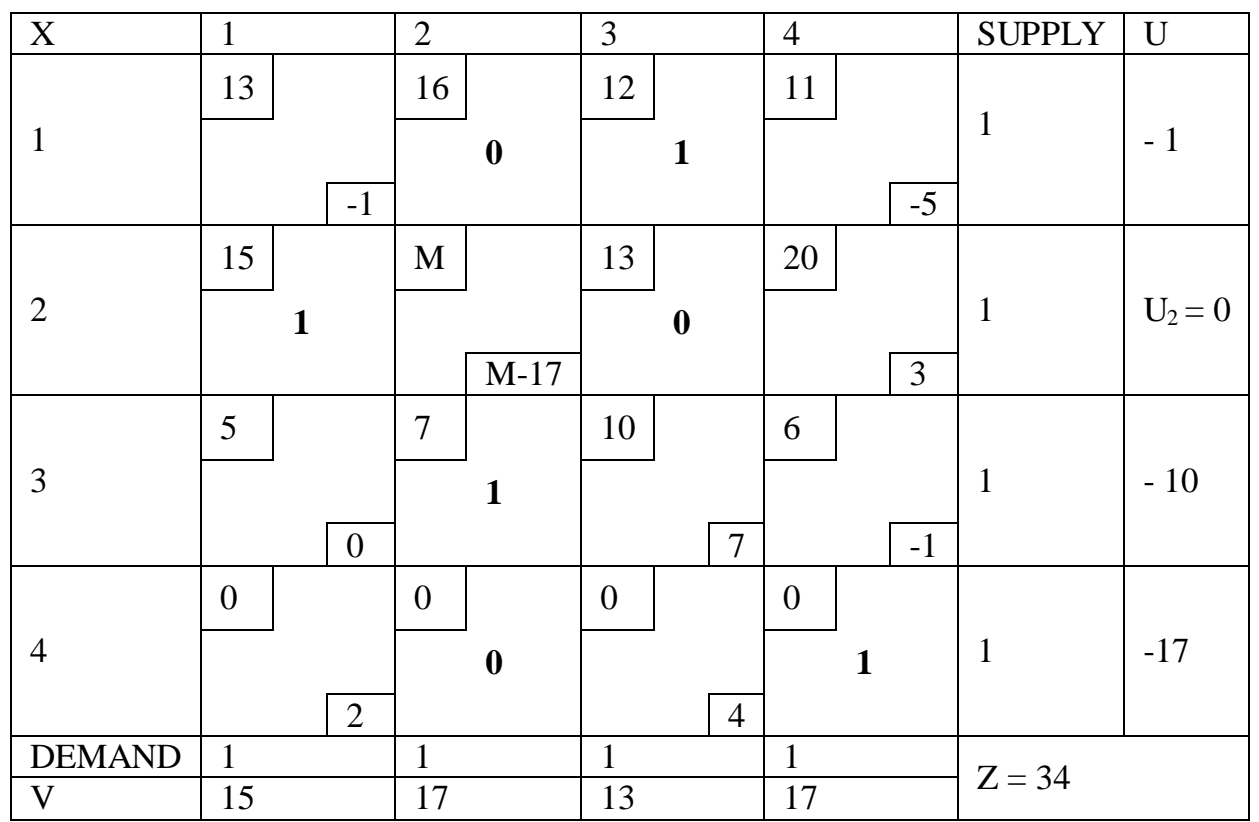

Let,

$\mathrm{U} 2=0$

Now, $\mathrm{c}_{\mathrm{ij}}=\mathrm{u}_{\mathrm{i}}+\mathrm{v}_{\mathrm{j}}$

Now, $\mathrm{c}_{11}=\mathrm{u}_{1}+\mathrm{v}_{1}$ 
$\Rightarrow \mathrm{v}_{1}=15$ and so on.

Here, for the non basic cells 14 the values of $c_{i j}-u_{i}-v_{j}<0$. So the solution is not optimal.

Table 3. Results Comparison for IBF between the Methods

\begin{tabular}{|c|c|c|c|c|c|}
\hline \multicolumn{6}{|l|}{ Example 1} \\
\hline \multicolumn{2}{|c|}{ Northwest Corner } & \multicolumn{2}{|c|}{ Russell Method } & \multicolumn{2}{|l|}{ New Method } \\
\hline No. Entries & Z Value & No. Entries & Z Value & No. Entries & Z Value \\
\hline 8 & $2470+\mathrm{M}$ & 8 & 2570 & 11 & 2560 \\
\hline \multicolumn{6}{|l|}{ Example 2} \\
\hline \multicolumn{2}{|c|}{ Northwest Corner } & \multicolumn{2}{|c|}{ Russell Method } & \multicolumn{2}{|l|}{ New Method } \\
\hline No. Entries & Z Value & No. Entries & Z Value & No. Entries & Z Value \\
\hline 8 & $209+25 \mathrm{M}$ & 8 & 305 & 9 & 305 \\
\hline \multicolumn{6}{|l|}{ Example 3} \\
\hline \multicolumn{2}{|c|}{ Northwest Corner } & \multicolumn{2}{|c|}{ Russell Method } & \multicolumn{2}{|l|}{ New Method } \\
\hline No. Entries & Z Value & No. Entries & Z Value & No. Entries & Z Value \\
\hline 6 & 48 & 6 & 32 & 8 & 34 \\
\hline \multicolumn{6}{|c|}{ Example 4} \\
\hline \multicolumn{2}{|c|}{ Northwest Corner } & \multicolumn{2}{|c|}{ Russell Method } & \multicolumn{2}{|l|}{ New Method } \\
\hline No. Entries & Z Value & No. Entries & Z Value & No. Entries & Z Value \\
\hline 7 & $23+\mathrm{M}$ & 7 & 29 & 11 & 34 \\
\hline
\end{tabular}

\section{Conclusion}

As it was shown there were two leading methods for solving the transportation problems by finding the initial basic feasible solution (IBF). Both these methods (Russell Method, and Northwest Corner rule) had drawbacks. However, the proposed new method is able to get the IBF value without any drawback in the sense that all the required number of entries needed to initiate the transportation simplex algorithm. Hence, this method can be a good substitution for the existing leading methods - Russell method and Northwest Corner Rule.

\section{Appendix I. References}

Hillier, F.S. and Lieberman, G.J. (2005). Introduction to operations Research. McGraw-Hill Publishing Company.

\section{Appendix II. Notation}

The following symbols are used in this paper:

$\mathrm{C}_{\mathrm{ij}} \quad=\quad$ Cell allocation

$\mathrm{i} \quad=\quad$ subscript denoting variables;

$\mathrm{IBF} \quad=\quad$ initial basic feasible solution;

$\mathrm{j} \quad=\quad$ subscript denoting variables;

$\mathrm{M}=$ the largest unknown unit cost;

$\mathrm{m} \quad=\quad$ number of rows;

$\mathrm{n} \quad=\quad$ number of columns;

$\overline{u i}=\quad$ the largest unit cost $\mathrm{c}_{\mathrm{ij}}$ remaining in row

$\overline{v j} \quad=\quad$ the largest unit cost $\mathrm{c}_{\mathrm{ij}}$ remaining in column;

$\Delta i j=c i j-\overline{u i}-\overline{v j}$;

$\mathrm{Z}=$ initial basic feasible solution 
A Comprehensive Method for Arriving at Initial Feasible Solution for Optimization Problems in Engineering with Illustrative Examples

\section{References}

1. Maatuk, A.M., Idrees, H.S., \& Ali, E.H. (2016). An optimal solution for transportation problem using computing modelling. In International Conference on Engineering \& MIS (ICEMIS), 1-5. https://doi.org/10.1109/ICEMIS.2016.7745340.

2. Ali, M. (2014). Comparison Between Some Methods Used in Solving Transportation Problem. International Journal of Mathematics Trends and Technology, 44(7).

3. Choudhary, B. (2016). Optimal Solution of Transportation Problem. International Journal of Innovative Research in Science, Engineering and Technology, 5(8).

4. Davda, P., \& Patel, J. (2019). Developed Method for Optimal Solution of Transportation Problem. International Research Journal of Engineering and Technology (IRJET) 6(3), 1880-1882.

5. Flötteröd, G. (2017). A search acceleration method for optimization problems with transport simulation constraints. Transportation Research Part B: Methodological, 98, 239-260.

6. https://doi.org/10.1016/j.trb.2016.12.009.

7. Patel, R.G., Bhathawala, P.H., \& Patel, B.S. An Alternate Approach to Find an Optimal Solution of a Transportation Problem. IOSR Journal of Mathematics (IOSR-JM), 13(1), 1-5.

8. https://doi.org/10.9790/5728-1301030105

9. Ghazali, Z., Amin, A.B.D., Majid, M., \& Shazwani, M. (2012). Optimal solution of transportation problem using linear programming: A case of a Malaysian trading company. Journal of Applied Science, 12(23), 2430-2435.

10. Gleyzal, A. (1955). An algorithm for solving the transportation problem. Journal of Research of the National Bureau of Standards, 54(4), 213-216. https://doi.org/10.6028/jres.054.025

11. Kumar, R., Gupta, R., \& Karthiyayini, O. (2018). A new approach to find the initial basic feasible solution of a transportation problem. International Journal of Research-Granthaalayah, 6(5), 321-325. https://doi.org/10.5281/zenodo.1283413

12. Maatuk, A.M., Idrees, H.S., \& Ali, E.H. (2016). An optimal solution for transportation problem using computing modelling. In International Conference on Engineering \& MIS (ICEMIS), 1-5.

13. https://doi.org/10.1109/ICEMIS.2016.7745340

14. Hanif, M., Rafi, F.S. (2018). A New Method for Optimal Solutions of Transportation Problems in LPP. 10, 60-75. https://doi.org/10.5539/jmr.v10n5p60

15. Hasan, M.K. (2012). Direct Methods for Finding Optimal Solution of a Transportation Problem are not Always Reliable. International Refereed Journal of Engineering and Science (IRJES), 1(2), 46-52, 2319-182.

16. Hillier, F., \& Lieberman, G. (2001). Introduction to Operations Research. McGraw-Hill Higher Education.

17. Juman, Z.A.M.S., \& Nawarathne, N.G.S.A. (2019). An efficient alternative approach to solve a transportation problem. Ceylon journal of Science 48(1), 19-29.

18. Malireddy, M. (2018). The Optimum Solution of Degenerate Transportation Problem. International organization of Scientific Research International organization of Scientific Research, 8(8), 2278-8719.

19. Mishra, S. (2017). Solving transportation problem by various methods and their comparison. International Journal of Mathematics Trends and Technology, 44(4), 270-275.

20. Nikolai, M. (2016). Asymptotically Optimal Solution for Transportation Problem with Almost Arbitrary Capacities. IFAC-PapersOnLine, 49(13), 270-274.

21. Putcha, C., Putcha, A.K., Bhuiyan, M.R.A., \& Hoque, N.F. (2010). Development of a new optimal method for solution transportation problems. In Proceedings of the World Congress on Engineering, 3.

22. Putcha, C.S., \& Shekharamiz, A. (2009). Development of a new method for arriving at Initial basic feasible Solution for optimization problems in Engineering, 23rd European Conference on Operational Research, Bonn, 5-8.

23. Raigar, S., Duraphe, S., \& Modi., G. (2017). The advanced method for finding optimum solution for transportation problem, International journal of Statistics and Applied Mathematics, 1(2): 43-45

24. Revelle, C.S., Whitlatch, E., \& Wright, J.R. (2004). Civil and Environmental Systems Engineering. McGraw-Hill, 2nd Edition.

25. Seethalakshmy, A., \& Srinivasan, N. (2018). A heuristic approach to obtain an optimal solution for transportation problem using assignment. Taga Journal, 14, 1862-1870.

26. Chanas, S., \& Kuchta, D. (1996). A concept of the optimal solution of the transportation problem with fuzzy cost coefficients. Fuzzy sets and systems, 82(3), 299-305.

27. Sirisha, J., Viola, A. (2018). A Novel Method to find an Optimal Solution for Transportation Problemsan Experiment. International Journal of Pure and Applied Mathematics, 118(24), 1-7.

28. Amaravathy, A., Thiagarajan, K., \& Vimala, S. (2016). MDMA Method-An Optimal Solution for Transportation Problem. Middle-East Journal of Scientific Research, 24(12), 3706-3710. 
29. Ullah, M.W., Kawser, R., \& Uddin, M.A. (2015). A Direct Analytical Method for Finding an Optimal Solution for Transportation Problems. Journal of mechanics of continua and mathematical sciences, 9 , 1311-1320. https://doi.org/10.26782/jmcms.2015.01.00006.

30. Joshi, R.V. (2013). Optimization techniques for transportation problems of three variables. IOSR Journal of Mathematics, 9(1), 46-50. https://doi.org/10.9790/5728-0914650

31. Yadav, D., Kumar, S. (2017). A Case Study on the Optimization of the Transportation Cost for Raipur steel and thermal power plant. International Journal of Research in Medical Sciences, 5(9), 768-776.

32. Zak, J., Jaszkiewicz, A., \& Redmer, A. (2009). Multiple criteria optimization method for the vehicle assignment problem in a bus transportation company. Journal of Advanced Transportation, 43(2), 203243.

33. Zhang, X., Li, L., \& Zhang, J. (2019). An optimal service model for rail freight transportation: Pricing, planning, and emission reducing. Journal of Cleaner Production, 218, 565-574. 